\title{
Gene silencing of indoleamine 2,3-dioxygenase 1 inhibits lung cancer growth by suppressing T-cell exhaustion
}

\author{
$\mathrm{KE} \mathrm{SHANG}^{1}$, ZHIGANG WANG ${ }^{2}$, YINYING HU ${ }^{2}$, YANQIN HUANG ${ }^{2}, \mathrm{KENG} \mathrm{YUAN}^{2}$ and YANRONG YU $^{2}$ \\ ${ }^{1}$ Department of Rheumatology and Immunology, Jiangxi Provincial People's Hospital Affiliated to Nanchang University; \\ ${ }^{2}$ Department of Immunology, Jiangxi Academy of Medical Sciences, Nanchang, Jiangxi 330006, P.R. China
}

Received May 1, 2019; Accepted February 7, 2020

DOI: $10.3892 /$ ol.2020.11477

\begin{abstract}
Indoleamine 2,3-dioxygenase 1 (IDO1), which degrades the essential amino acid tryptophan, exerts immunosuppressive functions and serves a crucial role in multiple types tumor progression, including non-small-cell lung cancer (NSCLC) and melanoma. Recent studies have reported that T-cell exhaustion is increased during tumor progression, which impairs the antitumor immune response. However, the association between IDO1 and T-cell exhaustion during tumor progression remains unknown. The present study evaluated the effect of IDO1 on T-cell exhaustion in lung cancer mice. The present study demonstrated that IDO1 knockdown by small interfering RNA in the LLC cell line inhibited T-cell exhaustion. Furthermore, the role of IDO1 in T-cell exhaustion during lung cancer progression was determined in an in vivo mouse model using IDO1 short hairpin RNA (shRNA). The results demonstrated that inhibition of IDO1 activity by shRNA administration in vivo significantly delayed the onset and growth of tumors. In addition, the expression levels of the inhibitory receptors programmed death-1 (PD-1) and B and $\mathrm{T}$ lymphocyte attenuator (BTLA) were increased in T-cells from the lung tumor-bearing mice, whereas interleukin-2 (IL-2) and tumor necrosis factor-alpha (TNF- $\alpha$ ) levels in serum were decreased compared with the control mice. However, no difference in the absolute number of $\mathrm{T}$ cells was observed, including $\mathrm{CD}^{+}$and $\mathrm{CD}^{+} \mathrm{T}$ cells. In addition, IDO1 knockdown by shRNA inhibited T-cell exhaustion in lung tumor-bearing mice, which was characterized by decreased expression of PD-1 and BTLA on T cells. By contrast, IL-2 and TNF- $\alpha$ levels in serum were increased in IDO1-shRNA-treated mice. By using a shRNA approach, the present study demonstrated that IDO1 activity may be involved in tumor growth, and that IDO1 silencing may inhibit tumor progression by impeding the process of T-cell exhaustion.
\end{abstract}

Correspondence to: Dr Yanrong Yu, Department of Immunology, Jiangxi Academy of Medical Sciences, 461 Bayi Road, Nanchang, Jiangxi 330006, P.R. China

E-mail: yuyanrong1988@163.com

Key words: lung cancer, indoleamine 2,3 dioxygenase 1, T-cell exhaustion, immunotherapy

\section{Introduction}

Lung cancer is the most common cancer worldwide. Although various types of therapy have been used for its treatment, the mortality rate remains high; in 2018, there were 234,030 new lung cancer cases and 154,050 lung cancer-associated deaths reported in the United States (1). It is therefore crucial to further investigate the underlying mechanisms of lung cancer development.

Indoleamine-2,3-dioxygenase 1 (IDO1) is a rate-limiting metabolic enzyme that converts tryptophan into downstream catabolites known as kynurenines (2). It has been reported that kynurenines can inhibit the activity and proliferation of $\mathrm{T}$ cells and other immune cells, such as dendritic cells $(3,4)$, leading to successful tumor escape from immune surveillance. The tumor microenvironment (TME) is a complicated environment of proliferating tumor cells that also contains a number of immune cells stimulating cancer progression by tumor immune escape. IDO1 is highly expressed in human lung cancer tissue (5) and has been reported to elicit immunosuppressive effects and favor tumor progression in animal models of lung cancer (6). Our previous study has found that IDO1 is highly expressed in mouse LLC cells. The immunosuppression effect of IDO1 in LLC cells is associated with regulatory T-cell expansion, which serves a crucial role in tumorigenesis and tumor development (7).

T-cell exhaustion is a process that occurs during tumor progression and chronic viral infections, in which $\mathrm{T}$ cells lose their ability to kill cancer or virus-infected cells upon chronic antigen exposure $(8,9)$. T-cell exhaustion is characterized by the increased expression of numerous inhibitory receptors, including programmed death-1 (PD-1) $(10,11)$, B and T lymphocyte attenuator (BTLA) (11), T-cell immunoglobulin domain and mucin domain 3 (TIM3) (10), lymphocyte-activation gene 3 (12), CD244 (13) and cytotoxic T lymphocyte antigen-4 (CTLA4) (13). In addition, the secretion of certain cytokines, including interleukin-2 (IL-2), tumor necrosis factor- $\alpha$ (TNF- $\alpha$ ) and interferon- $\gamma($ IFN- $\gamma)(13-15)$, is decreased during T-cell exhaustion. Recently, immunotherapy has demonstrated considerable promise in the management of various types of malignancy, including NSCLC and hepatocellular carcinoma $(16,17)$. Recent studies have reported that inhibition of T-cell exhaustion is an important form of cancer immunotherapy $(18,19)$. An increasing number of recognized immune 
checkpoint inhibitors, including those of PD-1 and CTLA4, affect the local tumor immune environment by blocking the PD-1/PD-L1 and CTLA4 signaling pathways and have been used to treat certain types of cancer, including melanoma (20), non-small-cell lung cancer (21) and urothelial cancer (22). These immune checkpoint inhibitors can restore T-cell antitumor activity by suppressing T-cell exhaustion. At present, an increasing number of new immune checkpoint inhibitors are being discovered, including LAG-3 (23), TIM-3 (24) and TIGIT (24).

The role of IDO1 in the immune escape mechanism of cancer was first introduced in 2002 by Friberg et al (25), who reported that LLC cells stimulated a stronger allogeneic T-cell response when cultured in the presence of an IDO1 inhibitor, leading to a delay in LLC tumor growth following systemic treatment in vivo. Furthermore, IDO-knockout mice presented with reduced tumor size and inhibited expression of $\mathrm{CD}^{+}$and CD8+-PD1 in tumor-infiltrating T-cells (26). These studies suggested that IDO1 may serve a crucial role in T-cell response during tumorigenesis; however, the association between IDO1 and T-cell exhaustion in the tumor microenvironment remains unknown and requires further investigation.

In the present study, the role of IDO1 in T-cell exhaustion during tumor progression was investigated, with the aim to clarify the association between IDO1 expression levels and lung cancer. In addition, the present study investigated whether IDO1 can inhibit lung cancer growth by suppressing T-cell exhaustion in the lung tumor-bearing mice which may inform the development of IDO1-targeted molecular therapy to inhibit T-cell exhaustion of lung cancer.

\section{Materials and methods}

Cell lines and mice. The Lewis Lung Carcinoma (LLC) cell line was purchased from The Cell Bank of Type Culture Collection of the Chinese Academy of Sciences and was authenticated by conventional tests of cell line quality control methods (morphology, isoenzymes, mycoplasma). Cells were cultured in Dulbecco's modified Eagle's medium (Gibco; Thermo Fisher Scientific, Inc.) containing $10 \%$ fetal bovine serum, $2 \mathrm{mmol} / \mathrm{l} \mathrm{L-glutamine}$ and $100 \mathrm{U} / \mathrm{ml}$ penicillin/streptomycin (all Gibco; Thermo Fisher Scientific, Inc.) placed at $37^{\circ} \mathrm{C}$ in a humidified incubator containing $5 \% \mathrm{CO}_{2}$.

A total of nine female C57BL/6 mice (aged 6-8 weeks, weighing 15-20 g) were purchased from The Shanghai SLAC Laboratory Animal Co., Ltd. The use of all mice in the present study followed the Regulations for the Administration of Affairs Concerning Experimental Animals of China, and Ethics approval from the Institutional Animal Care and Use Committee of Jiangxi Academy of Medical Sciences in China was obtained. The mice were housed in a specific pathogen-free animal facility affiliated to Jiangxi Academy of Medical Sciences with a controlled temperature of $25^{\circ} \mathrm{C}$, $50-65 \%$ relative humidity and a $12-\mathrm{h}$ light/dark cycle. The mice had ad libitum access to sterile water and food.

IDO1 transfection with small interfering (si)RNA. siRNA targeting IDO1 and luciferase gene glabra 2 (GL2; GL2-siRNA) were designed and synthesized by GE Healthcare Dharmacon, Inc. The GL2-siRNA, which was not expressed in treated cells (scrambled siRNA), was used as a negative control. The sequences of the siRNA were as follows: IDO1 siRNA, 5'-GGG CUUCUUCCUCGUCUCUTT-3' and GL2 siRNA, 5'-CGU ACGCGGAAUACUUCGA-3'. These siRNAs were transfected into LLC cells with Lipofectamine ${ }^{\circledR} 2000$ reagent (Invitrogen; Thermo Fisher Scientific, Inc.). Briefly, LLC cells (1x10 $/$ well) were seeded into 12-well plates until they reached 50-70\% confluence. Before transfection, medium was replaced with $300 \mu 1$ OptiMEM $^{\circledR}$ serum-reduced medium (Gibco; Thermo Fisher Scientific, Inc.). Subsequently, $1 \mu \mathrm{g}$ IDO1-siRNA or GL2-siRNA was incubated with $2 \mu$ l Lipofectamine ${ }^{\circledR} 2000$ reagent in $200 \mu \mathrm{l} \mathrm{OptiMEM}^{\circledR}$ serum-reduced medium at room temperature for $20 \mathrm{~min}$, followed by addition of the mixture to the cells that were gently agitated to distribute the mixture uniformly for $24 \mathrm{~h}$.

Extraction of IDOI $\mathrm{mRNA}$ and reverse transcription-quantitative $(R T-q) P C R$. Total RNA was extracted from cells using Invitrogen TRIzol ${ }^{\circledR}$ Reagent (Invitrogen; Thermo Fisher Scientific, Inc.). For mRNA quantification, $1 \mu \mathrm{g}$ total RNA was transcribed into cDNA using MMLV Reverse Transcriptase kit (Invitrogen; Thermo Fisher Scientific, Inc.) according to the manufacturers' instructions. The sequences of the primers were as follows: $\beta$-actin forward 5'-AGGGAAATCGTGCGT GACAT-3' and reverse, 5'-AACCGCTCGTTGCCAATA GT-3'; IDO1 forward, 5'-GTACATCACCATGGCGTATG-3' and reverse, 5'-CGAGGAAGAAGCCCTTGTC-3'. QPCR was performed using SYBR ${ }^{\circledR}$ Green PCR Master Mix (Takara Bio, Inc.) in a final volume of $20 \mu \mathrm{l}$ on the Bio-Rad CFX96TM Real-Time System (Bio-Rad Laboratories, Inc.). The amplification conditions were $95^{\circ} \mathrm{C}$ for $30 \mathrm{sec}, 60^{\circ} \mathrm{C}$ for $30 \mathrm{sec}$ and $72^{\circ} \mathrm{C}$ for $15 \mathrm{sec}$ for 45 cycles. The expression levels of mRNA were normalized to $\beta$-actin. The relative expressions level of IDO1 was normalized to endogenous control and was expressed as $2^{-\Delta \Delta \mathrm{Cq}}(27)$.

Western blotting. LLC cells were lysed using RIPA buffer (Beijing Solarbio Science \& Technology Co., Ltd.) containing PMSF protease inhibitor $(1 \mathrm{mmol} / \mathrm{l})$. Protein concentration was determined by using the bicinchoninic acid protein assay (Bio-Rad Laboratories, Inc.). Proteins $(30 \mu \mathrm{g})$ were separated by $8 \%$ SDS-PAGE and transferred to PVDF membranes. The membranes were blocked with 5\% nonfat milk and 3\% BSA in TBST $(0.25 \%$ Tween-20) and subsequently incubated overnight at $4^{\circ} \mathrm{C}$ with the following primary antibodies: Mouse anti-human IDO1 mAb (cat. no. sc-53978; 1:200; Santa Cruz Biotechnology, Inc.) and mouse anti-human $\beta$-actin $\mathrm{mAb}$ (cat. no. sc-47778; 1:2,000; Santa Cruz Biotechnology, Inc.). The membranes were washed three times with TBST and incubated with the secondary antibody, goat anti-mouse IgG-HRP (cat. no. sc-358914; 1:5,000; Santa Cruz Biotechnology, Inc.), at room temperature for $2 \mathrm{~h}$. Enhanced chemiluminescence reagent (OriGene Technologies, Inc.) was used to detect the signal on the membrane. The relative expression levels of the IDO1 protein were calculated using the gray scale ratio of IDO1/ $\beta$-actin using ImageJ version 1.46 software (National Institutes of Health).

shRNA expression vector treatment. All mice were successfully modeled and randomly divided into a control group (no 
treatment group) $(\mathrm{n}=3)$, a scrambled-shRNA treatment group $(n=3)$ and an IDO1-shRNA treatment group $(n=3)$ (28). Briefly, C57BL/6 mice were treated with $40 \mu \mathrm{g}$ IDO1- or scrambled-shRNA (GE Healthcare Dharmacon, Inc.) dissolved in $1 \mathrm{ml}$ PBS by hydrodynamic tail intravenous injection 3 days before cancer inoculation, $5 \times 10^{5}$ LLC cells resuspended in $0.1 \mathrm{ml}$ PBS were injected subcutaneously into the upper hind leg of all C57BL/6 mice (28). On days 7, 14 and 21 following cancer cell inoculation, expect the control group mice (no treatment), mice were injected with $40 \mu \mathrm{g}$ IDO1-shRNA or scrambled-shRNA dissolved in $1 \mathrm{ml}$ PBS by hydrodynamic tail intravenous injection. Tumor size was measured with a caliper every other day, and the tumor volume was calculated as follows $(29,30)$ : Tumor volume $=0.5 \mathrm{x}$ (tumor length) $\mathrm{x}$ (tumor width) ${ }^{2}$. Tumor onset was considered to have occurred when the tumor diameter reached $5 \mathrm{~mm}$. On day 21 , all mice were sacrificed with $30 \% / \mathrm{min}$ carbon dioxide for $\sim 180 \mathrm{sec}$ prior to cervical dislocation $(31,32)$ and were confirmed dead based on cardiac arrest and respiratory arrest 40-60 sec later. Tumors, lymph nodes and spleens were collected, tumors were weighed and tumor volumes were measured. These tissues were stored at $-80^{\circ} \mathrm{C}$ for further experiments. The shRNA sequences were as follows: IDO1 shRNA, 5'-GGGCUUCUUCCUCGUCUC UTT-3' and scramble-shRNA, 5'-CGUACGCGGAAUACU UCGA-3'.

Co-culture of LLC cells and lymphocytes in vitro. LLC cells were seeded in 12-well plates at a density of $1 \times 10^{5}$ cells/well for $24 \mathrm{~h}$ and were transfected with IDO1- or GL2-siRNA. After $24 \mathrm{~h}$ of transfection, lymphocytes isolated from the spleen of LLC-bearing C57BL/6 mice (33). Briefly, spleens $(\sim 1 \mathrm{~cm}$ in length and $30 \mathrm{~mm}$ in width) were placed on a $40 \mu \mathrm{m}$ Falcon Cell Strainer (VWR International, LLC.) and gently squashed with a plunger. The cell suspension was collected to centrifuge at $4^{\circ} \mathrm{C}, 250 \mathrm{~g}$ for $5 \mathrm{~min}$, then further isolated using ACK Lysing Buffer (Beijing Solarbio Science \& Technology Co., Ltd.) to lyse red blood cells. Lymphocytes were added to the LLC cells at a density of $5 \times 10^{5}$ cells/well and were cultured at $37^{\circ} \mathrm{C}$ with $5 \% \mathrm{CO}_{2}$ for $48 \mathrm{~h}$. Lymphocytes were subsequently collected and stained with anti-CD4-FITC (cat. no. 553047; 1:200; BD Pharmingen; BD Biosciences), anti-CD8-PE (cat. no. 12-0081-82; 1:200; eBioscience; Thermo Fisher Scientific, Inc.), anti-PD-1-APC (cat. no. 17-9985-82; 1:200; eBioscience; Thermo Fisher Scientific, Inc.) and anti-BTLA-PE (Cat. no. 12-5950-82; 1:200; eBioscience; Thermo Fisher Scientific, Inc.), incubated at $4^{\circ} \mathrm{C}$ in dark for $30 \mathrm{~min}$, then detected using flow cytometry (BD FACSCanto II; BD Biosciences). The data were analyzed suing FlowJo version 10 software (Becton, Dickinson and Company).

Immunohistochemistry (IHC) staining. Tumor tissues collected from lung tumor-bearing mice on day 21 were fixed in $4 \%$ paraformaldehyde at $4^{\circ} \mathrm{C}$ for $24 \mathrm{~h}$ and embedded in paraffin. The 4-7 $\mu \mathrm{m}$ sections were deparaffinized and endogenous peroxidase activity was quenched using a $3 \%$ $\mathrm{H}_{2} \mathrm{O}_{2}$ solution at $20^{\circ} \mathrm{C}$ for $20 \mathrm{~min}$. The antigens were retrieved using a sodium citrate buffer $(0.01 \mathrm{M}, \mathrm{pH} 6.0)$ in a pressure cooker $\left(100^{\circ} \mathrm{C}\right)$ for $15 \mathrm{~min}$ and tissue sections were incubated with an IDO1 primary antibody (cat. no. sc-53978; 1:50; Santa Cruz Biotechnology, Inc.) for $16 \mathrm{~h}$ at $4^{\circ} \mathrm{C}$. The sections were washed three times with PBS, incubated with ready to use enzyme-conjugated streptavidin (cat. no. 14C12B01; Boster Biological Technology) at $37^{\circ} \mathrm{C}$ for $30 \mathrm{~min}$, washed three times with PBS and stained with 3'-diaminobenzidine. Subsequently, the degree of immunostaining was scored according to the proportion of positively stained tumor cells and the intensity of staining. The percentage of tumor cell staining was scored as 0 (negative), 1 (weak), 2 (moderate) and 3 (strong) for $0,<25$, 26-50 and $>50 \%$ of positively stained cancer cells, respectively. The final staining score was calculated as follows: Staining score=intensity score $\mathrm{x}$ percentage score.

Phenotypic flow cytometry analysis. To assess T-cell exhaustion, on day 21 following LLC cell injection in C57BL/6 mice, lymphocytes from the lymph node and the spleen were collected from mice. Single-cell suspensions were prepared as aforementioned and analyzed using flow cytometry, the detailed experimental procedures for cells prepared, stained and analyzed were described in the 'Co-culture of LLC cells and lymphocytes in vitro' section.

Secreted cytokine detection by ELISA. The serum was obtained from the mice blood as follows. After anesthesia, 0.5-1 ml blood was collected from the eyeballs of mice, which was kept at room temperature for $2 \mathrm{~h}$, then centrifuged at $3,000 \mathrm{x} g$ for $10 \mathrm{~min}$ to separate the serum. The concentration of TNF- $\alpha$ and IL-2 in mouse serum was performed using Quantikine Mouse TNF- $\alpha$ (cat. no. 88-7324-88; Invitrogen, Thermo Fisher Scientific, Inc.) and IL-2 Immunoassay kits (cat. no. 88-7024-88; Invitrogen, Thermo Fisher Scientific, Inc.) according to the manufacturer's instructions. Briefly, ELISA plates were coated with capture antibody, blocked with ELISA/ELISPOT Diluent, incubated with detection antibody and washed, serum cytokines were detected by incubation with Avidin-HRP at room temperature for $30 \mathrm{~min}$. Plates were then washed, substrate was added and plates were read at $450 \mathrm{~nm}$ using microplate reader (Molecular Devices).

Statistical analysis. Data are presented as the mean \pm standard deviation and were analyzed using GraphPad Prism 5 (GraphPad Software, Inc.). Student's t-test (two-tailed unpaired) was used to compare the differences between two groups. One-way ANOVA was used to compare $\geq 3$ groups followed by Tukey's post-hoc test. $\mathrm{P}<0.05$ was considered to indicate a statistically significant difference.

\section{Results}

IDO1-siRNA decreases IDO1 expression in vitro. To confirm IDO1 knockdown by IDO1-siRNA in LLC cells, IDO1 mRNA and protein expression was assessed by RT-qPCR and western blotting, respectively. As presented in Fig. 1A, IDO1 expression level in LLC cells transfected with IDO1-siRNA was significantly decreased compared with the control group $(\mathrm{P}<0.05)$. In addition, IDO1 protein expression was significantly decreased following IDO1-siRNA transfection compared with the control (Fig. 1B).

IDO1-siRNA inhibits T-cell exhaustion in vitro. To determine the effect of IDO1 knockdown on T-cell exhaustion, LLC cells 
A

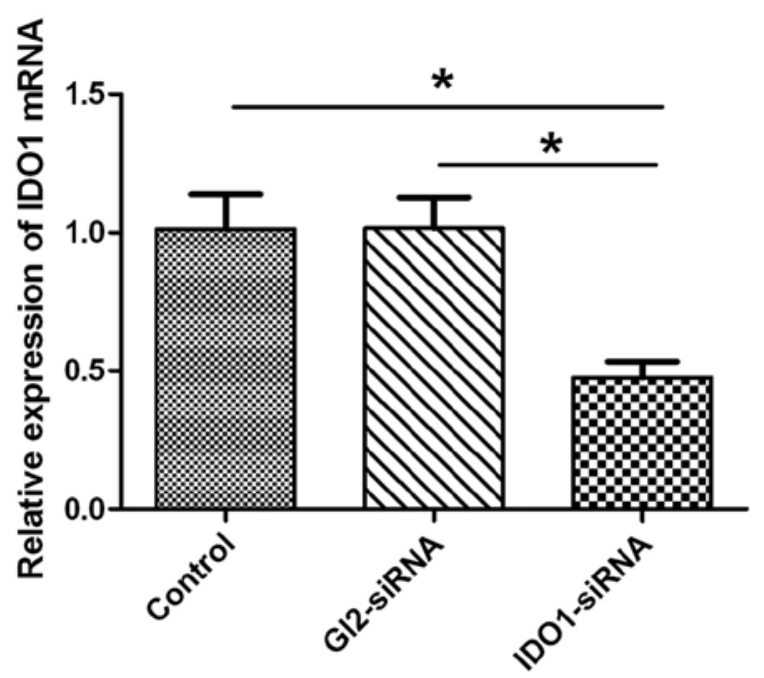

B

\section{Control GI2-siRNA IDO1-siRNA}
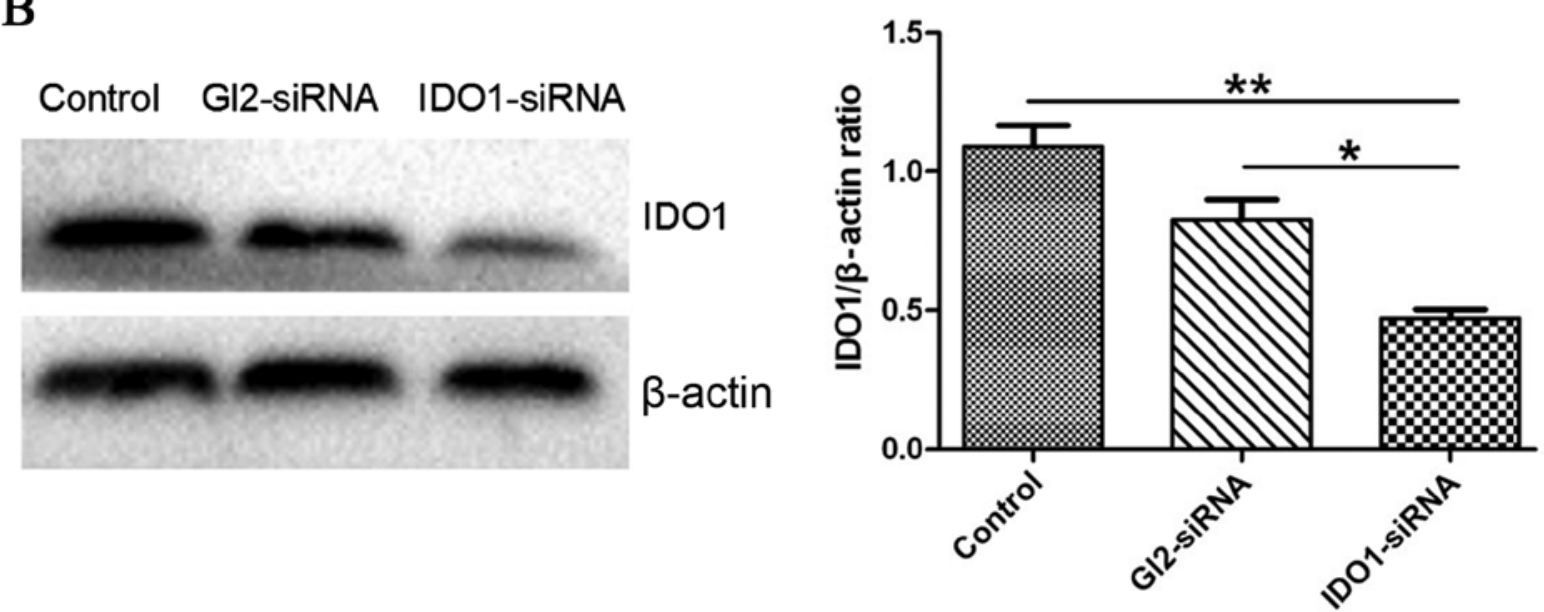

Figure 1. IDO1-siRNA silences IDO1 expression in vitro. (A) IDO1 mRNA expression. LLC cells were transfected with IDO1-siRNA or GL2-siRNA (negative control). Untransfected cells were used as a blank control. IDO1 mRNA expression level was detected by reverse transcription-quantitative PCR (n=3). (B) IDO1 protein expression. Silencing of IDO1 was confirmed by western blotting $(\mathrm{n}=3)$ in LLC cells after transfection with IDO1-siRNA, GL2-siRNA or blank control. " $\mathrm{P}<0.05$ and ${ }^{* *} \mathrm{P}<0.01$. GL2, glabra 2; IDO1, indoleamine 2,3-dioxygenase 1; siRNA, small interfering RNA.

treated with IDO1-siRNA, GL2-siRNA and the untreated control group were co-cultured with $\mathrm{T}$ cells isolated from the spleen of LLC tumor-bearing mice. T cells were collected, and the expression of inhibitory receptors PD-1 and BTLA, which are markers of T-cell exhaustion, was assessed by flow cytometry. The results demonstrated that PD-1 and BTLA expression in $\mathrm{CD}^{+} \mathrm{T}$ cells (PD-1, 8.37 $\pm 1.17 \%$; BTLA, $5.06 \pm 0.47 \%$ ) in the co-culture of IDO1-siRNA LLC cells and T cells was decreased compared with the control (PD-1, 16.8 $2.3 \%$; BTLA, 7.83 $\pm 1.07 \%$ ) and scrambled GL2-siRNA group (PD-1, $15.8 \pm 1.18 \%$; BTLA, $7.34 \pm 1.02 \%$; Fig. 2A and B). These results demonstrated that IDO1-siRNA in LLC cells inhibited T-cell exhaustion in vitro.

IDOI-shRNA transfection suppresses lung cancer growth in vivo. The present study evaluated the therapeutic effect of IDO1 knockdown by using IDO1-shRNA to treat tumor-bearing mice. The IDO1 staining score of IDO1-shRNA-treated mice was decreased compared with that of scrambled-shRNA-treated mice and the untreated control group (Fig. 3A and B), confirming the efficiency of IDO1 knockdown in tumor tissues. Furthermore, in
IDO1-shRNA-treated mice, the time of tumor onset was delayed (Fig. 3C), and tumor growth was significantly slower compared with that of scrambled-shRNA-treated mice and control group (Fig. 3D). In addition, tumor size in IDO1-shRNA-treated mice was decreased compared with scrambled-shRNA-treated mice and the control group (Fig. 3E), and tumor weight was significantly decreased in IDO1-shRNA-treated mice compared with the other two groups (Fig. 3F). These results suggested that intravenous injection of IDO1-shRNA may inhibit lung cancer growth in mice.

The presence of tumors increases the expression of $P D-1$ and BTLA on CD4+ and CD8+T cells in vivo. To determine the role of LLCs in the T-cell immune response, C57BL/6 mice were inoculated subcutaneously with $5 \times 10^{5}$ LLC cells into the upper hind leg, whereas animals were injected with PBS as the no tumor group. Lymphocytes from the lymph nodes and the spleen were harvested and stained for $\mathrm{CD}^{+}, \mathrm{CD}^{+}$and the inhibitory receptors PD-1 and BTLA to analyze T cells in LLC tumor-bearing mice and no tumor mice by flow cytometry. The results demonstrated that the percentages of $\mathrm{CD}^{+}$and $\mathrm{CD} 8^{+} \mathrm{T}$ cells were similar in 
A
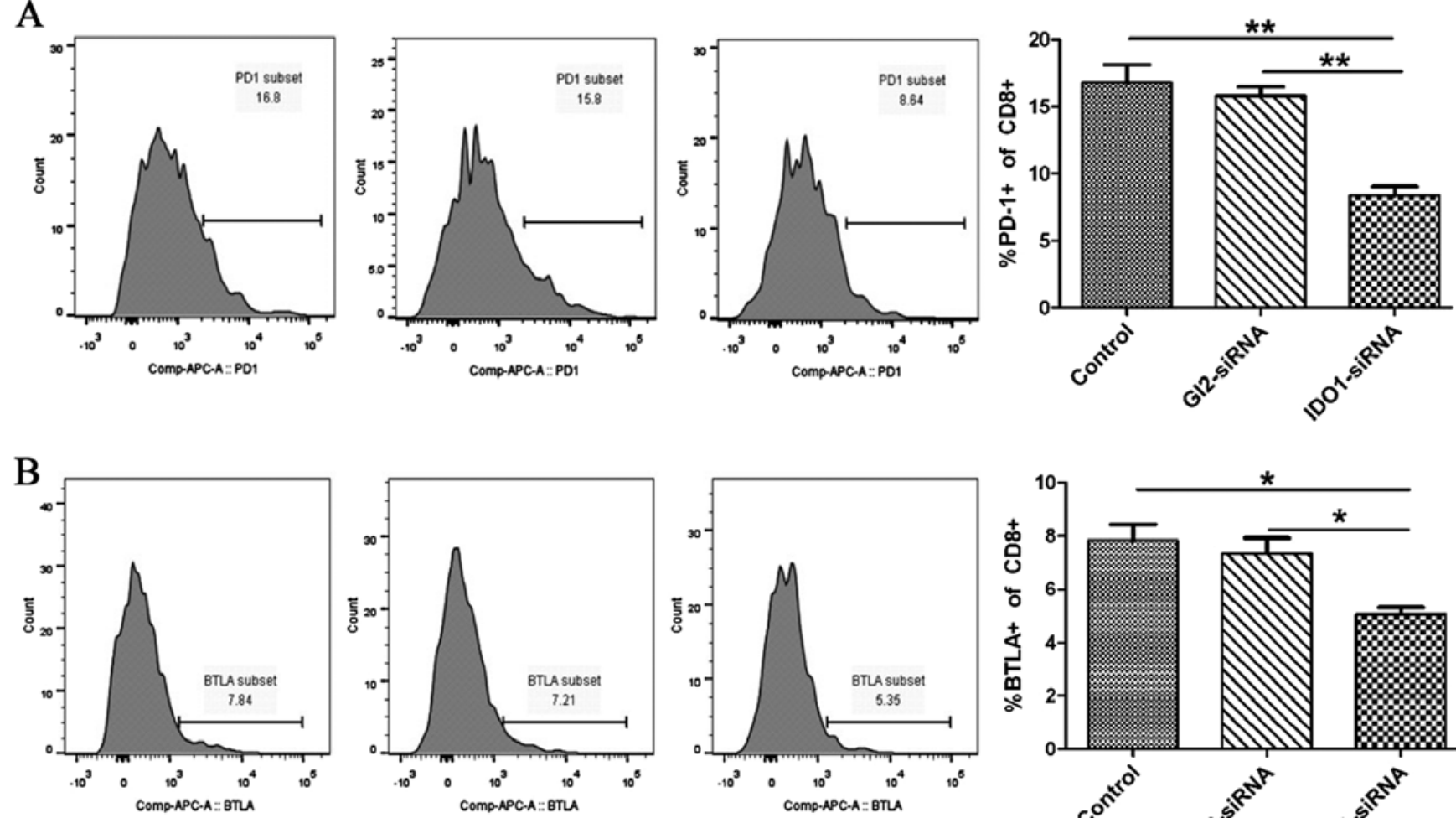

Figure 2. IDO1-siRNA in LLC cells inhibits T-cell exhaustion in vitro. (A and B) LLC cells were transfected with IDO1-siRNA or GL2-siRNA and co-cultured with lymphocytes isolated from spleen. Lymphocytes were collected and (A) PD-1 and (B) BTLA were detected by flow cytometry. $n=3$. " $\mathrm{P}<0.05$ and ${ }^{* *} \mathrm{P}<0.01$. BTLA, B and T lymphocyte attenuator; GL2, glabra 2; IDO1, indoleamine 2,3-dioxygenase 1; PD-1, programmed death-1; siRNA, small interfering RNA; control, untransfected cells.

tumor-bearing mice and mice without tumors (Fig. 4A and B). Furthermore, mice with tumors presented with an increased percentage of $\mathrm{PD}-1^{+}, \mathrm{CD} 4^{+}$and $\mathrm{BTLA}^{+}$on $\mathrm{CD} 4^{+} \mathrm{T}$ cells from the lymph nodes and the spleen compared with that in healthy mice (Fig. 4C): in the lymph nodes, the percentage of $\mathrm{PD}^{+}$cells was $17.2 \pm 0.9$ vs. $9.9 \pm 0.5 \%$, and that of $\mathrm{BTLA}^{+}$cells was $37.3 \pm 0.5$ vs. $31.8 \pm 1.2 \%$ in mice with tumor vs. mice without tumors, respectively. In the spleen, the percentage of $\mathrm{PD}^{+}$cells was $10.7 \pm 0.6$ vs. $7.2 \pm 0.2 \%$, and that of $\mathrm{BTLA}^{+}$cells was $1.5 \pm 0.2$ vs. $0.7 \pm 0.05 \%$ in mice with tumor vs. mice without tumors, respectively. Similar results were observed in $\mathrm{CD}^{+} \mathrm{T}$ cells (Fig. 4D), the percentage of $\mathrm{PD}^{+}$cells from the lymph node was $9.9 \pm 1.0 \mathrm{vs} .5 .1 \pm 0.5 \%$ and that of $\mathrm{BTLA}^{+}$cells was $21.4 \pm 1.5$ vs. $14.5 \pm 0.6 \%$ in mice with tumors vs. mice without tumors, respectively. In the spleen, the percentage of $\mathrm{PD}^{+}$cells was $2.2 \pm 0.1$ vs. $1.5 \pm 0.1 \%$, and that of $\mathrm{BTLA}^{+}$cells was $2.6 \pm 0.3$ vs. $1.1 \pm 0.1 \%$ in mice with tumors vs mice without tumors, respectively. These results demonstrated that tumors did not alter the number of $\mathrm{CD}^{+}$and $\mathrm{CD}^{+} \mathrm{T}$ cells in the lymph nodes or the spleen. However, the expression of PD1 and BTLA on $\mathrm{CD}^{+}$and $\mathrm{CD}^{+}$T cells was increased in the TME. Taken together, these results suggested that T-cell exhaustion may occur in lung TME.

Treatment with IDO1-shRNA decreases co-inhibitory receptor expression on $C D 4^{+} / C D 8^{+} T$ cells in vivo. In the present study, IDO1-shRNA decreased the tumor size of tumor-bearing mice. Subsequently, IDO1-shRNA treatment was applied in vivo, as well as scrambled-shRNA treatment and absence of treatment (control). Lymphocytes from the lymph nodes and the spleen of LLC-bearing tumor mice were collected on day 21 to detect the expression of PD-1 and BTLA in $\mathrm{CD}^{+}{ }^{+}$and $\mathrm{CD}^{+}{ }^{+} \mathrm{T}$ cells by flow cytometry. The expression of PD-1 and BTLA on CD4 ${ }^{+}$cells of lymph nodes from IDO1-shRNA-treated mice was significantly decreased compared with scrambled-shRNA-treated mice $(16.8 \pm 0.6$ to $12.7 \pm 0.9$ and $35.8 \pm 2.3$ to $16.8 \pm 1.8 \%$, respectively; Fig. 5A). The expression of PD-1 and BTLA on $\mathrm{CD}^{+} \mathrm{T}$ cells of lymph nodes from IDO1-shRNA-treated mice was significantly lower compared with that of mice treated with scrambled-shRNA $(9.2 \pm 1.2$ to $4.8 \pm 0.7$ and $32.6 \pm 1.0$ to $17.4 \pm 4.0 \%$, respectively; far right-hand graph, Fig. 5C). Furthermore, PD-1 and BTLA expression on $\mathrm{CD}^{+} \mathrm{T}$ cells from the spleen was also significantly decreased in IDO1-shRNA-treated mice compared with scrambled-shRNA-treated mice and the control group (no treatment) (Fig. 5B). These results demonstrated that IDO1-shRNA suppressed T-cell exhaustion by inhibiting the expression of co-inhibitory receptors.

Treatment with IDO1-shRNA recovers cytokine production in vivo. One characteristic of T-cell exhaustion is the impaired production of cytokines (15). To determine whether treatment with IDO1-shRNA in tumor-bearing mice increased cytokine production in the TME, serum from untreated tumor-bearing mice (control), scrambled-shRNA- or and IDO1-shRNA treated mice was collected. Subsequently, serum TNF- $\alpha$ and IL-2 levels were analyzed by ELISA. The results demonstrated 


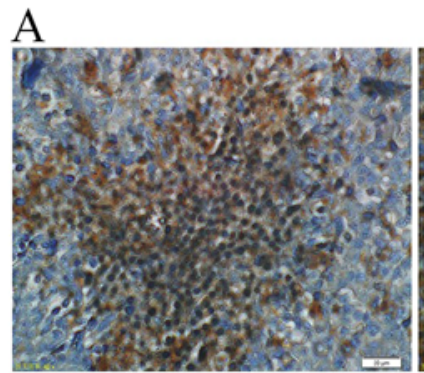

Control

C

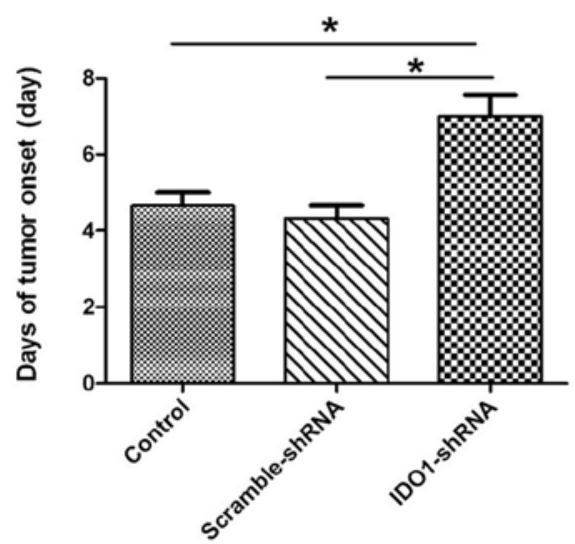

E

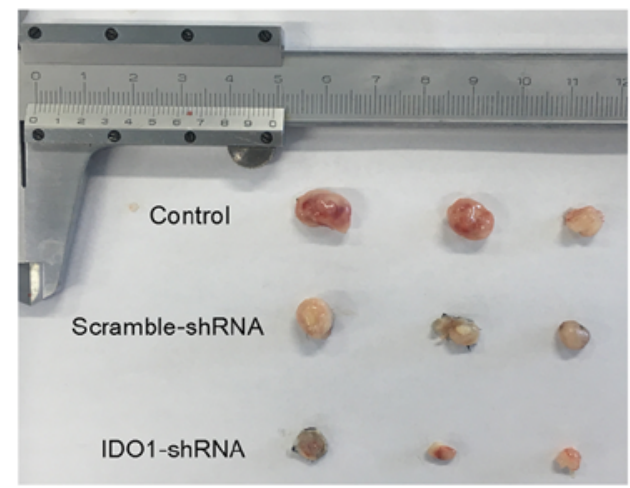

B

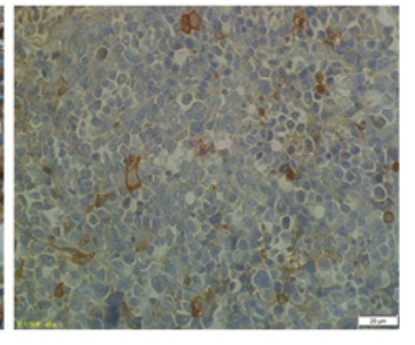

IDO1-shRNA

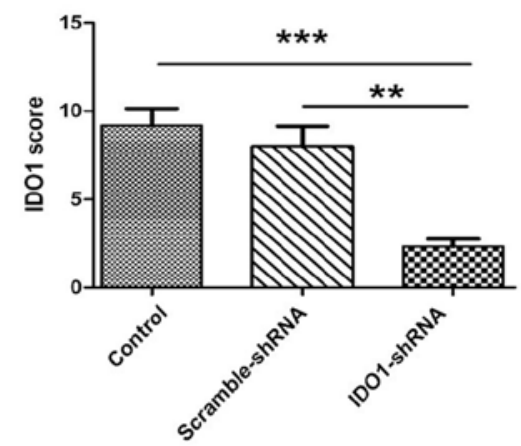

$\mathrm{D}$

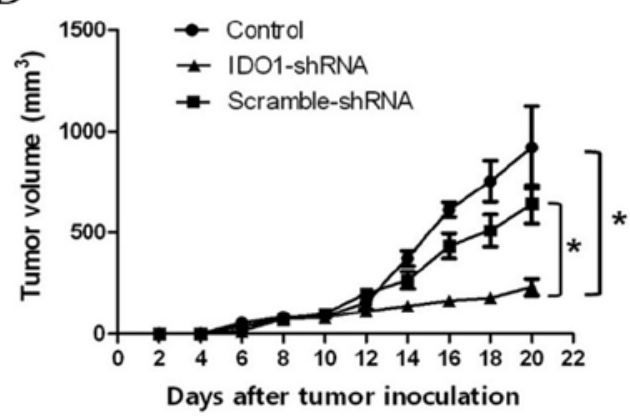

$\mathrm{F}$

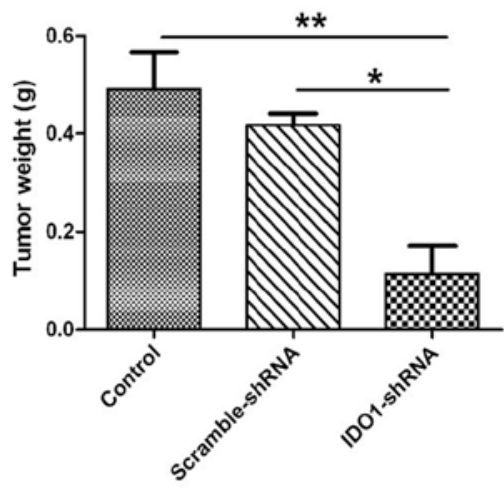

Figure 3. Treatment with IDO1-shRNA inhibits lung cancer growth in vivo. Treatment with IDO1 or scrambled expression vectors was performed by hydrodynamic intravenous tail injection. (A) Tumor tissues were collected from lung cancer-bearing mice after 21 days. Expression of IDO1 in tumors was detected by immunohistochemistry (magnification, x40). (B) IDO1 expression scores. (C) Time of tumor onset was recorded when the tumor diameter reached $5 \mathrm{~mm}$. (D) Tumor growth curve. (E) Images of tumors. At day 21 after LLC cell inoculation, the mice were sacrificed, and the tumors were measured with a caliper. (F) Tumor weights were measured after 21 days. ${ }^{*} \mathrm{P}<0.05,{ }^{* * *} \mathrm{P}<0.01$ and ${ }^{* * * *} \mathrm{P}<0.001$. IDO1, indoleamine 2,3-dioxygenase 1; shRNA, short hairpin RNA; control, untreated mice,

that the serum TNF- $\alpha$ and IL-2 levels in LLC-bearing mice were significantly lower compared with those in healthy mice (Fig. 6A and B). In addition, serum TNF- $\alpha$ and IL-2 levels in tumor-bearing mice treated with IDO1-shRNA were significantly increased compared with the control and scrambled-shRNA-treated mice (Fig. 6C and D). Furthermore, the TNF- $\alpha$ and IL-2 concentrations of mice treated with IDO1-shRNA returned to the level of mice without tumors (Fig. 6A, C and B,D). These data suggested that treatment with IDO1-shRNA recovered IL-2 and TNF- $\alpha$ production in vivo.

\section{Discussion}

IDO1 is an immunosuppressive regulatory factor in the TME, which allows tumor cells to escape immune surveillance (5).
T-cell exhaustion is a state of T-cell functional deficiency in tumors (34). At present, the effect of IDO1 on T-cell exhaustion remains unclear. In the present study, T-cell exhaustion was investigated in a murine lung cancer model. The results demonstrated the importance of IDO1 in T-cell exhaustion, and that IDO1 silencing may inhibit tumor growth by suppressing T-cell exhaustion.

IDO1 is a rate-limiting enzyme involved in the kynurenine pathway, which is a metabolic pathway that induces immunosuppression by degrading tryptophan in the tumor-draining lymph nodes and the TME (35). IDO1 is highly expressed in human lung cancer tissues (5) and a previous study reported that IDO1 downregulation in dendritic cells by gene silencing using an immune-stimulatory nanosystem can suppress tumor growth in lung cancer model (36). 
A

B
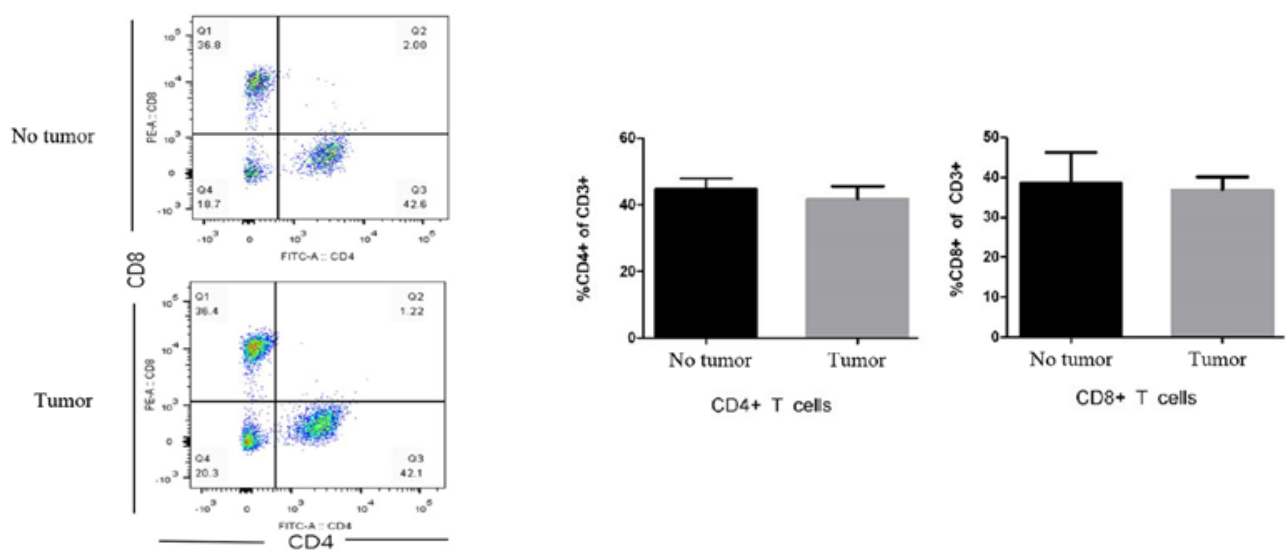

CD8+ T cells
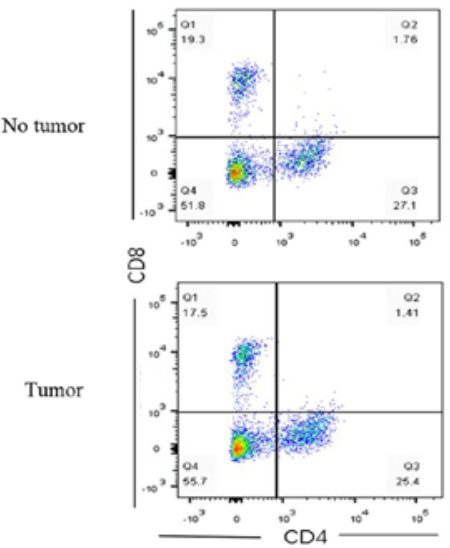

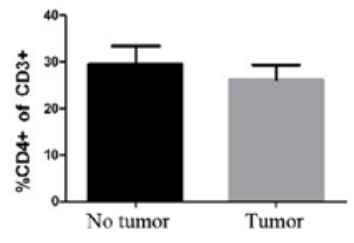

CD4+ T cells

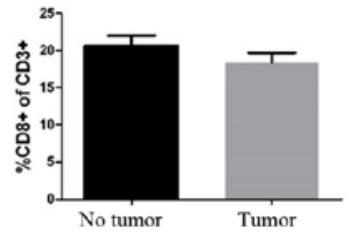

CD8+ $T$ cells
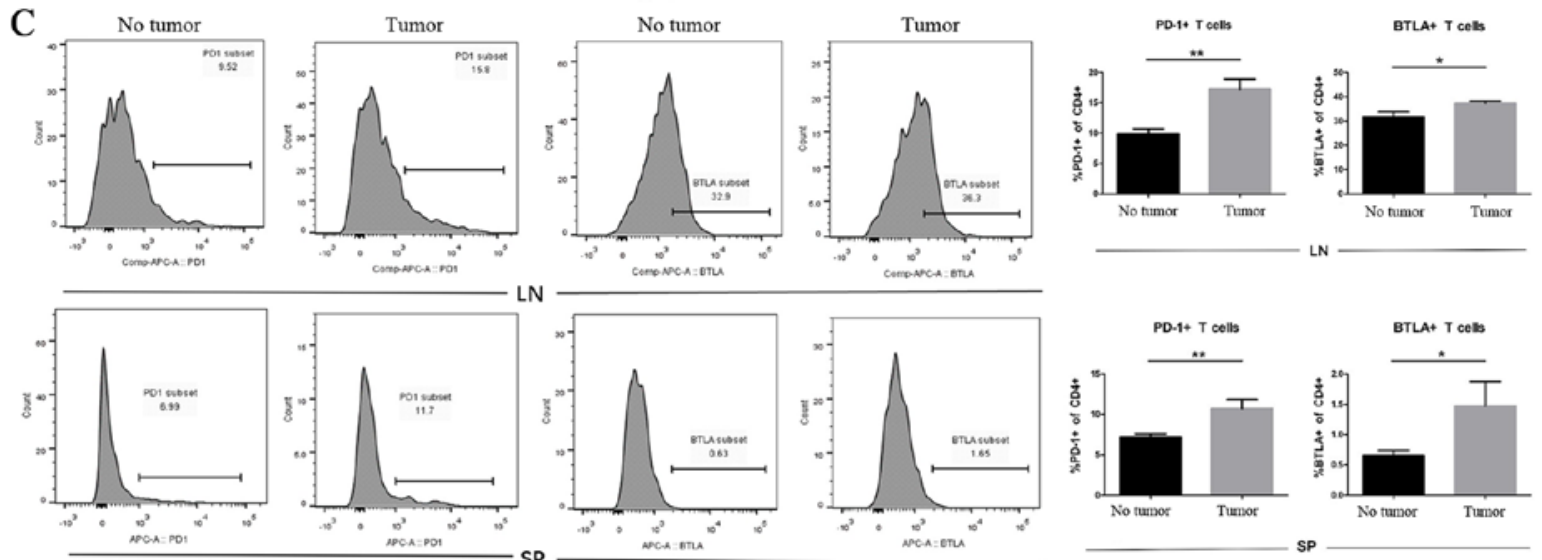

D
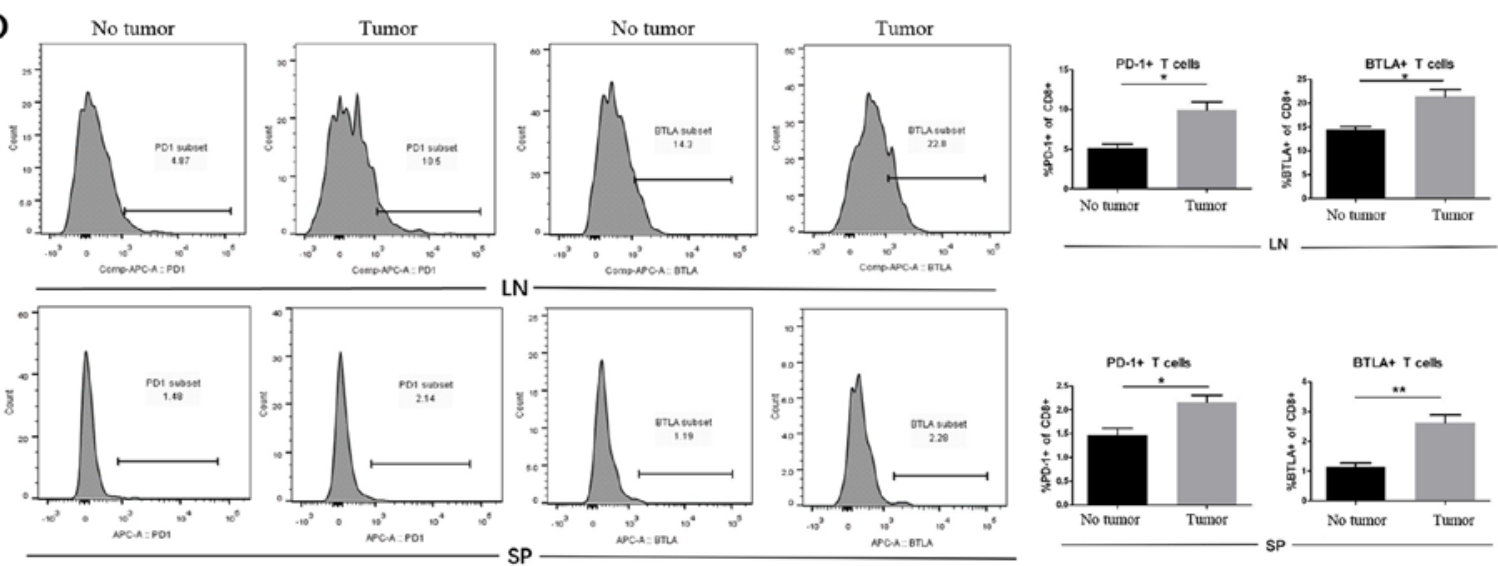

Figure 4. Tumors increase inhibitory receptor expression in both $\mathrm{CD}^{+}$and $\mathrm{CD}^{+} \mathrm{T}$ cells in vivo. Tumor-bearing mice were inoculated subcutaneously with LLC cells, and lymphocytes were collected for analysis after 21 days. Mice without tumors were used as the control. (A) Flow cytometry analysis of $\mathrm{CD}^{+} / \mathrm{CD}^{+}$lymphocytes from lymph nodes of $\mathrm{CD}^{+} \mathrm{T}$ cells in mice without tumors and mice with tumors. (B) Flow cytometry analysis of $\mathrm{CD} 4^{+} / \mathrm{CD} 8^{+}$ lymphocytes from the spleen of $\mathrm{CD}^{+} \mathrm{T}$ cells in mice without tumors and mice with tumors. (C and D) Percentage of PD1 and BTLA in CD4 ${ }^{+} / \mathrm{CD} 8^{+} \mathrm{T}$ cells from the lymph nodes and the spleen in mice without tumors vs. mice with tumors. ${ }^{*} \mathrm{P}<0.05$ and ${ }^{* *} \mathrm{P}<0.01$. BTLA, B and T lymphocyte attenuator; LN, lymph node; PD-1, programmed death-1; SP, spleen. 

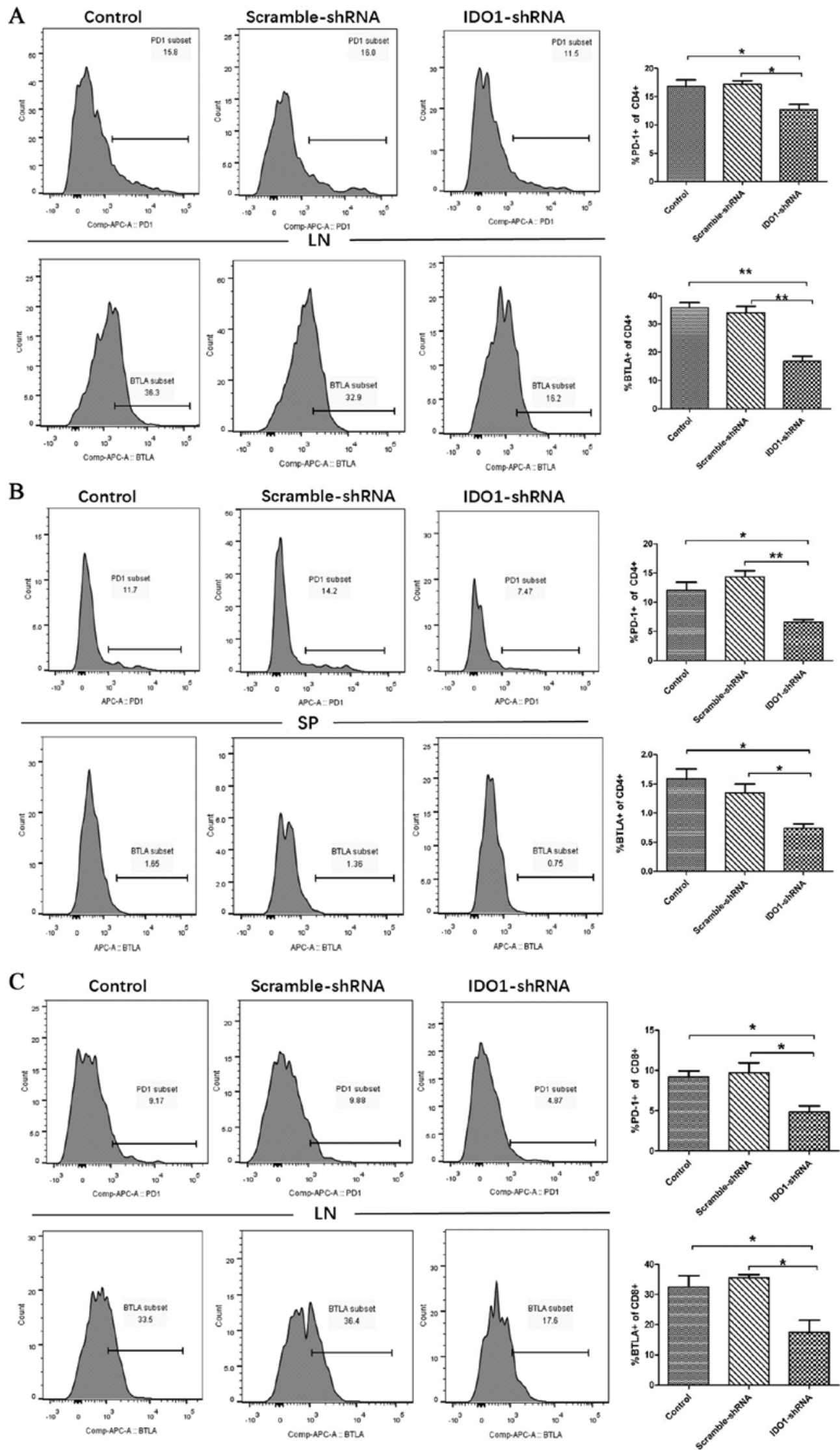

Figure 5. IDO1-shRNA treatment decreases the expression of inhibitory receptors of $\mathrm{CD} 4^{+} / \mathrm{CD} 8^{+} \mathrm{T}$ cells in vivo. Lymphocytes from lymph nodes and spleen of LLC-bearing tumor mice were collected on day 21 injection of LLC cells. CD4 ${ }^{+}$and CD8 ${ }^{+} \mathrm{T}$ cells were stained with anti-PD-1 and anti-BTLA and analyzed by flow cytometry. Expression of PD-1 and BTLA on $\mathrm{CD}^{+} \mathrm{T}$ cells in the (A) lymph nodes and (B) spleen of tumor-bearing mice without treatment, or treated with scrambled-shRNA or IDO1-shRNA. (C) Expression of PD-1 and BTLA on CD8 ${ }^{+} \mathrm{T}$ cells from the lymph nodes of tumor-bearing mice without treatment or treated with scrambled-shRNA or IDO1-shRNA. Statistical analysis of the expression of PD1 and BTLA on CD4 ${ }^{+}$(right panel in A and B) and CD8 ${ }^{+}$ (right panels in $\mathrm{C}$ ) was performed from three independent experiments. " $\mathrm{P}<0.05$ and ${ }^{* *} \mathrm{P}<0.01$. BTLA, B and $\mathrm{T}$ lymphocyte attenuator; IDO1, indoleamine 2,3-dioxygenase 1; LN, lymph node; PD-1, programmed death-1; sh, short hairpin; SP, spleen. 

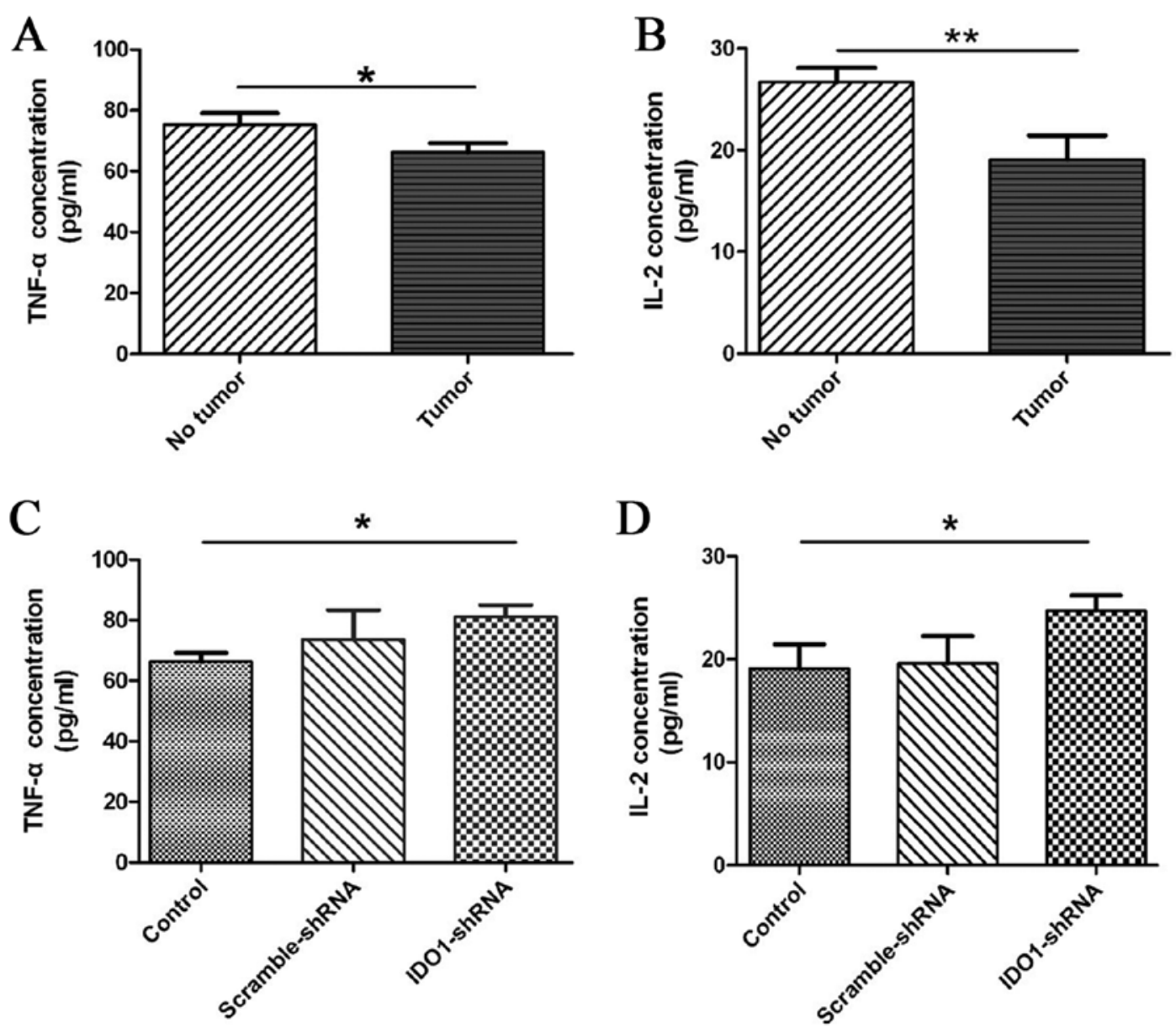

Figure 6. Treatment with IDO1-shRNA in tumor-bearing mice in vivo recovers cytokine secretion. C57BL/6 mice were treated with IDO1-shRNA or scrambled-shRNA by hydrodynamic intravenous tail injection. At day 21, blood from tumor-bearing control and treated mice was collected to detect the serum levels of TNF- $\alpha$ and IL-2 by ELISA. (A and B) Serum TNF- $\alpha$ and IL-2 levels in mice with and without tumors. (C and D) Serum TNF- $\alpha$ and IL-2 levels in the control mice, IDO1-shRNA- and scrambled-shRNA-treated mice. $\mathrm{n}=3$. ${ }^{*} \mathrm{P}<0.05$ and ${ }^{* * *} \mathrm{P}<0.01$. IL-2, interleukin-2; IDO1, indoleamine 2,3-dioxygenase; shRNA, short hairpin RNA; TNF- $\alpha$, tumor necrosis factor- $\alpha$.

These studies confirmed that IDO1 activity is involved in tumor growth. However, only a limited number of studies have investigated the role of IDO1 derived from tumor tissues or cells in lung cancer progression $(26,28)$, which mostly focused on metabolic reprogramming of immune cells or angiogenesis inhibition. In the present study, we investigated the effect of IDO1 derived from lung cancer on T-cells exhaustion. Our group has previously found that IDO1 is highly expressed in LLC cells (data not published). Ladomersky $\mathrm{E}$ reported inhibition of IDO1 activity by 1-methyl-tryptophan can increase patient survival (37); however, this treatment caused numerous adverse effects, including toxic and autoimmunity disease (38). The present study therefore attempted to knock down IDO1 by siRNA in LLC cells and verify whether IDO1-siRNA may silence IDO1 expression in vitro. Furthermore, the effect of IDO1 derived from tumor tissues on tumor growth was evaluated using shRNA interference, which is a mechanism of silencing gene expression resulting in sequence-specific mRNA interference (39). Hydrodynamic tail vein injection of various shRNA plasmids has been used as a treatment for prostate cancer, breast cancer and other diseases in mouse models (40). In the present study, IDO1 was knocked down in LLC tumor-bearing mice using shRNA. Results demonstrated that IDO1-shRNA treatment significantly delayed tumor onset and decreased tumor volume and weight compared to scramble-RNA treatment negative control. Furthermore, the results of the immunohistochemistry staining demonstrated that IDO1-shRNA treatment successfully knocked down IDO1 in tumor tissues. These results suggested that IDO1 may be silenced by injection of IDO1-shRNA into mice, therefore inhibiting tumor growth.

$\mathrm{T}$ cells that are reactive to tumor and viral antigens lose their reactivity when exposed to the antigen-rich environment of a larger tumor bed or viral load; such non-responsive $\mathrm{T}$ cells are considered exhausted (13). T-cell exhaustion is characterized by the upregulation of inhibitory molecules, including PD-1, BTLA and TIM3 $(41,42)$, and the reduced production of immune signaling molecules and cytokines, including TNF- $\alpha$, IL-2 and IFN- $\gamma(10,15)$. Therapeutic reinvigoration of tumor-specific $\mathrm{T}$ cells has greatly improved clinical outcomes in cancer (43). Previous studies in murine and human cancers have reported that suppressing T-cell exhaustion has a significant therapeutic effect on tumors by restoring the anti-tumor function of T cells $(34,44)$. In numerous models of malignant tumors, including malignant T-lymphoma and melanoma, the expression levels of PD-1 and BTLA were demonstrated to be associated with the 
decrease of tumor-specific T-cell effector function $(45,46)$. Blockage of both PD-1 and BTLA inhibitory pathways improves tumor-specific antigen immune responses and reverses T-cell exhaustion $(11,47)$. A previous study has suggested that the expression levels of PD-1, BTLA and 2B4 proteins in both $\mathrm{CD} 4^{+}$and $\mathrm{CD} 8^{+} \mathrm{T}$-cell compartments are increased in mice with localized cancer compared with healthy control (48). In the present study, lymphocytes from lymph nodes and spleen were collected from mice. These results demonstrated that tumors did not alter $\mathrm{CD}^{+}$and $\mathrm{CD} 8^{+} \mathrm{T}$-cell numbers in the lymph nodes and the spleen in LLC-bearing tumor mice compared with mice without tumors, but increased the expression of PD-1 and BTLA. These results suggested that T-cell exhaustion may occur in the lung TME. A previous study reported that IDO1 is highly expressed in tumors and plays an important role in the T-cell response to tumorigenesis (25). To further investigate the association between IDO1 and T-cell exhaustion in vitro, LLC cells transfected with IDO1-siRNA, G12-siRNA or control were co-cultured with $\mathrm{T}$ cells from LLC tumor-bearing mice. The results demonstrated that PD-1 and BTLA expression on $\mathrm{CD} 8^{+} \mathrm{T}$ cells was decreased in LLC cells following IDO1 knockdown, suggesting that IDO1 knockdown in LLC cells may suppress T-cell exhaustion during tumor progression. Furthermore, LLC tumor-bearing mice were treated with IDO1-shRNA in order to knock down IDO1 expression in tumors. The results demonstrated that IDO1 shRNA-treated mice presented with decreased expression of PD-1 and BTLA on $\mathrm{CD} 4^{+}$and $\mathrm{CD} 8^{+} \mathrm{T}$ cells, and suggested that IDO1-shRNA suppressed T-cell exhaustion by inhibiting the expression of co-inhibitory receptors.

Cytokines serve a crucial role in tumor cell proliferation. Exhausted T-cells progressively lose their functional capacity to proliferate and to produce cytokines, including TNF- $\alpha$, IL- 2 and IFN- $\gamma(41)$. It has been reported that IL-2 can reverse $\mathrm{CD}^{+} \mathrm{T}$-cell exhaustion in malignant pleural effusion of lung cancer (49). In the present study, serum TNF- $\alpha$ and IL-2 level in LLC tumor-bearing mice was decreased compared with healthy mice, suggesting TNF- $\alpha$ and IL-2 secretion may be inhibited in tumors in vivo, which is associated with T-cell exhaustion. In addition, the results of the present study demonstrated that treatment with IDO1-shRNA in LLC-bearing mice increased TNF- $\alpha$ and IL-2 production, compared with scrambled shRNA-treated mice and untreated control mice, and the concentrations of these cytokines after IDO1-shRNA treatment returned to the level of mice without tumors (healthy mice), These data suggested that treatment with IDO1-shRNA in vivo may recover cytokine secretion.

Some limitations of this study are the small sample size and the separation of T-cells. A total of nine female C57BL/6 mice in the present study were used and divided into three groups $(n=3)$. Although the small sample size was one of the limitations, the differences between each group were observed and the sample size was sufficient for statistical analysis to be performed, suggesting that the conclusions of the present study were reliable. A similar situation was previously reported, with a small sample size in their mice experiments $(n=3)(35)$. Regarding T-cells isolation, the present study used T-cells isolated from lymph nodes and spleen because extracting infiltrating T-cells from tumor tissues is difficult and only results in a small number of extracted T-cells. Therefore, extracting T-cells from lymph nodes and spleen was sufficient for the present study as this method has met the requirements of previous experiments $(47,50)$.

In summary, the results of the present study demonstrated that IDO1-shRNA delayed tumor onset and inhibited tumor growth by impeding T-cell exhaustion in a murine lung cancer model, which may be subsequent to the downregulation of T-cell inhibitory receptors PD-1 and BTLA and the upregulation of IL-2 and TNF- $\alpha$ secretion. These results suggested that IDO1-targeting molecular therapy may be combined with suppressive T-cell exhaustion therapy to treat patients with lung cancer, and that IDO1 knockdown by gene silencing may be considered as a promising treatment strategy for lung cancer.

\section{Acknowledgements}

Not applicable.

\section{Funding}

The present study was supported by the Youth Science Foundation of Jiangxi Province (grant no. 20181BAB215020), Jiangxi Provincial Department of Education Project (grant no. GJJ160268) and Jiangxi Provincial Health Department Project (grant no. 201715520).

\section{Availability of data and materials}

All data generated or analyzed during this study are included in this published article.

\section{Authors' contributions}

KS and YY conceived and designed the experiments. KS and $\mathrm{KY}$ performed the experiments. $\mathrm{YYH}$ and $\mathrm{YQH}$ participated in the model establishment. ZW conducted the statistical analysis. YY drafted the manuscript. All authors read and approved the final manuscript and agreed to be responsible for all aspects of the study in ensuring the accuracy or integrity of any part of the work are appropriately investigated and resolved.

\section{Ethics approval and consent to participate}

Animal experiments in the present study conformed to the Regulations on the Administration of Affairs Concerning Experimental Animals of China and were approved by the Biomedical Ethics Committee of Jiangxi Academy of Medical Sciences on Animal experiments (Nanchang, China).

\section{Patient consent for publication}

Not applicable.

\section{Competing interests}

The authors declare that they have no competing interests. 


\section{References}

1. Siegel RL, Miller KD and Jemal A: Cancer statistics, 2018. CA Cancer J Clin 68: 7-30, 2018.

2. Speeckaert R, Vermaelen K, van Geel N, Autier P, Lambert J, Haspeslagh M, van Gele M, Thielemans K, Neyns B, Roche N, et al: Indoleamine 2,3-dioxygenase, a new prognostic marker in sentinel lymph nodes of melanoma patients. Eur J Cancer 48: 2004-2011, 2012.

3. Platten M, von Knebel Doeberitz N, Oezen I, Wick W and Ochs K: Cancer immunotherapy by targeting IDO1/TDO and their downstream effectors. Front Immunol 5: 673, 2014.

4. Munn DH and Mellor AL: Indoleamine 2,3 dioxygenase and metabolic control of immune responses. Trends Immunol 34 137-143, 2013.

5. Munn DH and Mellor AL: IDO in the tumor microenvironment: Inflammation, counter-regulation, and tolerance. Trends Immunol 37: 193-207, 2016.

6. Smith C, Chang MY, Parker KH, Beury DW, DuHadaway JB, Flick HE, Boulden J, Sutanto-Ward E, Soler AP, Laury-Kleintop LD, et al: IDO is a nodal pathogenic driver of lung cancer and metastasis development. Cancer Discov 2: $722-735,2012$

7. Que Z, Zou F, Zhang A, Zheng Y, Bi L, Zhong J, Tian J and Liu J: Ganoderic acid Me induces the apoptosis of competent $\mathrm{T}$ cells and increases the proportion of Treg cells through enhancing the expression and activation of indoleamine 2,3-dioxygenase in mouse lewis lung cancer cells. Int Immunopharmacol 23: 192-204, 2014

8. Zajac AJ, Blattman JN, Murali-Krishna K, Sourdive DJ, Suresh M, Altman JD and Ahmed R: Viral immune evasion due to persistence of activated $\mathrm{T}$ cells without effector function J Exp Med 188: 2205-2213, 1998.

9. Pauken KE and Wherry EJ: Overcoming T cell exhaustion in infection and cancer. Trends Immunol 36: 265-276, 2015.

10. Sakuishi K, Apetoh L, Sullivan JM, Blazar BR, Kuchroo VK and Anderson AC: Targeting Tim-3 and PD-1 pathways to reverse T cell exhaustion and restore anti-tumor immunity. J Exp Med 207: 2187-2194, 2010

11. Fourcade J, Sun Z, Pagliano O, Guillaume P, Luescher IF, Sander C, Kirkwood JM, Olive D, Kuchroo V and Zarour HM: CD8(+) T cells specific for tumor antigens can be rendered dysfunctional by the tumor microenvironment through upregulation of the inhibitory receptors BTLA and PD-1. Cancer Res 72: 887-896, 2012

12. Matsuzaki J, Gnjatic S, Mhawech-Fauceglia P, Beck A, Miller A, Tsuji T, Eppolito C, Qian F, Lele S, Shrikant P, et al: Tumor-infiltrating NY-ESO-1-specific CD8+ T cells are negatively regulated by LAG-3 and PD-1 in human ovarian cancer. Proc Natl Acad Sci USA 107: 7875-7880, 2010.

13. Wherry EJ: T cell exhaustion. Nat Immunol 12: 492-499, 2011.

14. Yi JS, Cox MA and Zajac AJ: T-cell exhaustion: Characteristics, causes and conversion. Immunology 129: 474-481, 2010.

15. Balkhi MY, Ma Q, Ahmad S and Junghans RP: T cell exhaustion and Interleukin 2 downregulation. Cytokine 71: 339-347, 2015.

16. Li S, Zhang S, Liu J, Yang C, Zhang L and Cheng Y: The effect of PD-L1/PD-1 immunotherapy in the treatment of squamous non-small-cell lung cancer: A meta-analysis of randomized controlled clinical trials. J Thorac Dis 11: 4453-4463, 2019.

17. Yoon JS, Song JH, Yoon JH, Lee HY, Kim SW, Chang Y, Lee YB, Cho EJ, Yu SJ, Sinn DH, et al: Adjuvant cytokine-induced killer immunotherapy for hepatocellular carcinoma: A propensity score-matched analysis of real-world data. BMC Cancer 19: 523 , 2019.

18. Bu X, Yao Y and Li X: Immune checkpoint blockade in breast cancer therapy. Adv Exp Med Biol 1026: 383-402, 2017.

19. Mirzaei R, Sarkar S and Yong VW: T cell exhaustion in glioblastoma: Intricacies of immune checkpoints. Trends Immunol 38 104-115, 2017.

20. Robert C, Ribas A, Wolchok JD, Hodi FS, Hamid O, Kefford R, Weber JS, Joshua AM, Hwu WJ, Gangadhar TC, et al: Anti-p rogrammed-death-receptor-1 treatment with pembrolizumab in ipilimumab-refractory advanced melanoma: A randomised dose-comparison cohort of a phase 1 trial. Lancet 384: 1109-1117, 2014.

21. O'Connor JM, Seidl-Rathkopf K, Torres AZ, You P, Carson KR, Ross JS and Gross CP: Disparities in the use of programmed death 1 immune checkpoint inhibitors. Oncologist 23: 1388-1390, 2018.
22. Teo MY and Rosenberg JE: Nivolumab for the treatment of urothelial cancers. Expert Rev Anticancer Ther 18: 215-221, 2018.

23. Harris-Bookman S, Mathios D, Martin AM, Xia Y, Kim E, $\mathrm{Xu} \mathrm{H}$, Belcaid Z, Polanczyk M, Barberi T, Theodros D, et al: Expression of LAG-3 and efficacy of combination treatment with anti-LAG-3 and anti-PD-1 monoclonal antibodies in glioblastoma. Int J Cancer 143: 3201-3208, 2018.

24. Qin S, Xu L, Yi M, Yu S, Wu K and Luo S: Novel immune checkpoint targets: Moving beyond PD-1 and CTLA-4. Mol Cancer 18: 155,2019

25. Friberg M, Jennings R, Alsarraj M, Dessureault S, Cantor A, Extermann M, Mellor AL, Munn DH and Antonia SJ: Indoleamine 2,3-dioxygenase contributes to tumor cell evasion of T cell-mediated rejection. Int J Cancer 101: 151-155, 2002.

26. Schafer CC, Wang Y, Hough KP, Sawant A, Grant SC, Thannickal VJ, Zmijewski J, Ponnazhagan S and Deshane JS: Indoleamine 2,3-dioxygenase regulates anti-tumor immunity in lung cancer by metabolic reprogramming of immune cells in the tumor microenvironment. Oncotarget 7: 75407-75424, 2016

27. Livak KJ and Schmittgen TD: Analysis of relative gene expression data using real-time quantitative PCR and the 2(-Delta Delta $\mathrm{C}(\mathrm{T})$ ) method. Methods 25: 402-408, 2001

28. Pan J, Yuan K, Peng S, Huang Y, Zhang Y, Hu Y, Feng Y, Shi Y, Liu Y, Wang H, et al: Gene silencing of indoleamin 2,3-dioxygenase hinders tumor growth through angiogenesis inhibition. Int J Oncol 50: 2136-2144, 2017.

29. Naito S, von Eschenbach AC, Giavazzi R and Fidler IJ: Growth and metastasis of tumor cells isolated from a human renal cell carcinoma implanted into different organs of nude mice. Cancer Res 46: 4109-4115, 1986.

30. Escoffre JM, Novell A, Serrière S, Lecomte T and Bouakaz A: Irinotecan delivery by microbubble-assisted ultrasound: In vitro validation and a pilot preclinical study. Mol Pharm 10: 2667-2675, 2013.

31. American Veterinary Medical Association (AVMA): AVMA Guidelines for the Euthanasia of Animals: 2013 Edition. AVMA, Schaumburg, IL, 2013

32. Powell K, Ethun $\mathrm{K}$ and Taylor DK: The effect of light level, $\mathrm{CO}_{2}$ flow rate, and anesthesia on the stress response of mice during $\mathrm{CO}_{2}$ euthanasia. Lab Anim (NY) 45: 386-395, 2016.

33. Li Q, Johnston N, Zheng X, Wang H, Zhang X, Gao D and Min W: miR-28 modulates exhaustive differentiation of $\mathrm{T}$ cells through silencing programmed cell death-1 and regulating cytokine secretion. Oncotarget 7: 53735-53750, 2016.

34. Thommen DS and Schumacher TN: T cell dysfunction in cancer Cancer Cell 33: 547-562, 2018.

35. Muller AJ and Prendergast GC: Indoleamine 2,3-dioxygenase in immune suppression and cancer. Curr Cancer Drug Targets 7: 31-40, 2007.

36. Zhang Y, Fu J, Shi Y, Peng S, Cai Y, Zhan X, Song N, Liu Y, Wang Z, Yu Y, et al: A new cancer immunotherapy via simultaneous DC-mobilization and DC-targeted IDO gene silencing using an immune-stimulatory nanosystem. Int J Cancer 143: 2039-2052, 2018

37. Ladomersky E, Zhai L, Lenzen A, Lauing KL, Qian J, Scholtens DM, Gritsina G, Sun X, Liu Y, Yu F, et al: IDO1 inhibition synergizes with radiation and PD-1 blockade to durably increase survival against advanced glioblastoma. Clin Cancer Res 24: 2559-2573, 2018.

38. Jiang T, Sun Y, Yin Z, Feng S, Sun L and Li Z: Research progress of indoleamin 2,3-dioxygenase inhibitors. Future Med Chem 7: $185-201,2015$

39. Fire A, Xu S, Montgomery MK, Kostas SA, Driver SE and Mello CC: Potent and specific genetic interference by double-stranded RNA in Caenorhabditis elegans. Nature 391: 806-811, 1998

40. Vakili S, Ebrahimi SS, Sadeghi A, Gorgani-Firuzjaee S, Beigy M, Pasalar P and Meshkani R: Hydrodynamic-based delivery of PTP1B shRNA reduces plasma glucose levels in diabetic mice. Mol Med Rep 7: 211-216, 2013

41. Amezquita RA and Kaech SM: Immunology: The chronicles of T-cell exhaustion. Nature 543: 190-191, 2017.

42. Prall F and Hühns M: The PD-1 expressing immune phenotype of $\mathrm{T}$ cell exhaustion is prominent in the 'immunoreactive' microenvironment of colorectal carcinoma. Histopathology 71 : 366-374, 2017.

43. Yost KE, Spantidea PI, Wells DK, Qi Y, Wang C, Kageyama R, McNamara KL, Granja JM, Sarin KY, Brown RA, et al: Clonal replacement of tumor-specific T cells following PD-1 blockade. Nat Med 25: 1251-1259,2019. 
44. Hanahan D and Weinberg RA: Hallmarks of cancer: The next generation. Cell 144: 646-674, 2011.

45. Paulos $\mathrm{CM}$ and June $\mathrm{CH}$ : Putting the brakes on BTLA in T cell-mediated cancer immunotherapy. J Clin Invest 120: 76-80, 2010.

46. Karakatsanis S, Bertsias G, Roussou P and Boumpas D: Programmed death 1 and $\mathrm{B}$ and $\mathrm{T}$ lymphocyte attenuator immunoreceptors and their association with malignant T-lymphoproliferative disorders: Brief review. Hematol Oncol 32: 113-119, 2014.

47. Hamid O, Robert C, Daud A, Hodi FS, Hwu WJ, Kefford R, Wolchok JD, Hersey P, Joseph RW, Weber JS, et al: Safety and tumor responses with lambrolizumab (anti-PD-1) in melanoma. N Engl J Med 369: 134-144, 2013.

48. Mittal R, Chen CW, Lyons JD, Margoles LM, Liang Z, Coopersmith CM and Ford ML: Murine lung cancer induces generalized T-cell exhaustion. J Surg Res 195: 541-549, 2015 .
49. Hu CY, Zhang YH, Wang T, Chen L, Gong ZH, Wan YS, Li QJ, $\mathrm{Li}$ YS and Zhu B: Interleukin-2 reverses CD8(+) T cell exhaustion in clinical malignant pleural effusion of lung cancer. Clin Exp Immunol 186: 106-114, 2016.

50. Khalil DN, Suek N, Campesato LF, Budhu S, Redmond D, Samstein RM, Krishna C, Panageas KS, Capanu M, Houghton S, et al: In situ vaccination with defined factors overcomes $\mathrm{T}$ cell exhaustion in distant tumors. J Clin Invest 129: 3435-3447, 2019.

(i)(9) This work is licensed under a Creative Commons Attribution-NonCommercial-NoDerivatives 4.0 International (CC BY-NC-ND 4.0) License. 